\title{
ПСИХОЛОГИЯ
}

УДК 159.9.072

DOI: $10.21779 / 2542-0313-2018-33-1-95-100$

\section{М.К. Омарова}

\section{Жизнестойкость в её взаимосвязи с отдельными характеристиками личности}

Дагестанский государственный университет; Россия, 367001, 2. Махачкала, ул. М. Гаджиева, 43a; makaom@mail.ru

Статья посвящена исследованию проблемы жизнестойкости личности. Особенное внимание уделяется изучению взаимосвязи жизнестойкости с различными характеристиками индивида. В частности, рассматриваются такие особенности, как акцентуации характера, адаптивность, застенчивость, моральная нормативность и другие. Проблеме жизнестойкости достаточно много внимания уделяется в философии, чуть меньше она изучается в психологии и медицине. К примеру, представителями медицинской науки жизнестойкость рассматривается как один из показателей психического здоровья человека.

В статье представлены результаты эмпирического исследования взаимосвязи структурных компонентов жизнестойкости с указанными выше личностными характеристиками. В ходе подготовки работы автором использовались такие методы, как анализ психологической литературы, синтез, обобщение - теоретические методы; качественный анализ результатов исследования - практические методы исследования. Исследование проводилось на основе выборки студентов, средний возраст которых составил 17-19 лет. Для получения эмпирических данных были использованы методики, релевантные целям и задачам, поставленным нами в начале работы, и обладающие достаточно высокими уровнями валидности и надёжности. Применение методов математической обработки позволило получить достоверные показатели связи на высоком уровне статистической значимости. Анализ результатов показал наличие устойчивых корреляционных связей между структурными элементами жизнестойкости и следующими личностными характеристиками: реактивная агрессивность, застенчивость, моральная нормативность, циклоидная и лабильная акцентуации характера. Таким образом, можно сделать вывод, что с жизнестойкостью закономерно связаны личностные характеристики, отвечающие за стрессоустойчивость, эмоциональную стабильность и адаптивные способности индивида. Дальнейшие исследования феномена жизнестойкости необходимо расширить как в сторону выявления и изучения факторов, способствующих формированию данной особенности личности, так и в сторону изучения её формирования и развития на ранних этапах онтогенеза.

Ключевые слова: жизнестойкость, вовлечённость, контроль, принятие риска, личностные особенности.

Жизнестойкость - термин, приобретающий особенную актуальность в психологической науке именно на современном этапе существования российского общества. Экономический кризис, политическая нестабильность и социальная незащищенность абсолютного большинства жителей нашего государства являются значимыми факторами, оказывающими влияние на психологическую безопасность личности. В большинстве исследований жизнестойкость рассматривается как интегральная личностная характеристика, занимающая центральное место в процессе адаптации к активно меняю- 
щимся условиям среды, как способность индивида противостоять стрессу и, наконец, как показатель психического здоровья человека. О жизнестойкости довольно часто говорят в связи с проблемами копинг-поведения и выбора стратегий, адаптационного потенциала личности. Также данный феномен исследуется как личностный ресурс человека в процессе обучения [10].

Понятие жизнестойкости (hardiness) закономерно связывают с именами таких учёных, как С. Мадди и С. Кобейс, в конце XX века впервые обративших внимание на то, что выносливость и стойкость являются компонентами интегративного качества, позволяющего личности противостоять стрессу и сохранять внутреннюю гармонию. Структурные компоненты, характеризующие описываемое качество, по мнению данных авторов, - это вовлечённость, контроль и принятие риска.

Вовлеченность понимается как убеждённость личности в том, что активное участие в деятельности, глубокое погружение в работу дают возможность считать свою жизнь значимой и интересной, что, в свою очередь, позволяет успешно преодолевать актуальные и потенциальные стрессовые ситуации.

Контроль рассматривается как установка на уверенность в том, что управление собственной жизнью находится в руках самой личности.

И третий элемент - принятие риска, убеждённость в пользе любой жизненной ситуации, в которую попадает индивид, поскольку и позитивный, и негативный опыт одинаково важны для его личностного развития.

В отечественной психологии феномен жизнестойкости изучается относительно недавно и связан с именами Д.А. Леонтьева, Е.И. Рассказовой, Г.В. Ванаковой, Л.А. Александровой и др. [1, 2, 6, 11].

Наиболее полный анализ теоретических подходов к феномену жизнестойкости в отечественной и зарубежной психологии представлен в монографии А.Н. Фоминовой «Жизнестойкость личности» [12].

Александрова Л.А. понимает под жизнестойкостью интегральную способность, благодаря которой личность успешно адаптируется в различных жизненных ситуациях. При этом интегральная способность включает в себя блок общих способностей, состоящий из базовых личностных установок, самосознания, интеллекта, ответственности и смысла, а также блока специальных способностей, применяемых людьми в ситуациях межличностного взаимодействия и преодоления сложных обстоятельств жизни [1].

Как показали исследования, жизнестойкость связана с психологическим благополучием и успешной адаптацией личности в социуме. Кроме того, получены данные о её положительной корреляции с активными копинг-стратегиями, направленными на самостоятельное разрешение трудных жизненных ситуаций [3].

Маклаков А.Г. считает способность к адаптации личностным свойством человека [9, с. 16-24]. Причём им подчёркивается, что это не только процесс, но и свойство живой саморегулирующейся системы, состоящее в способности приспосабливаться к изменяющимся внешним условиям. Способности к адаптации зависят от психологических особенностей личности. Именно эти особенности определяют возможности адекватного регулирования физиологических состояний. Чем лучше развиты адаптационные способности, тем выше вероятность того, что организм человека сохранит нормальную работоспособность и высокую эффективность деятельности при воздействии психогенных факторов внешней среды [9].

Кудиновым С.И. и другими было проведено исследование жизнестойкости как предиктора самореализации в трудных жизненных ситуациях. Установлено, что в группе испытуемых с низкими показателями жизнестойкости отдельные её компоненты 
связаны с такими особенностями, как личностные цели самореализации, пессимистичность, экстернальный локус контроля, консервативность и эгоцентрическая мотивация. В группе респондентов с высоким уровнем жизнестойкости более ярко выражены оптимистичность, интернальность, активность, эгоцентрическая мотивация, креативность и конструктивность [6].

Для изучения взаимосвязи жизнестойкости с другими личностными характеристиками нами было также проведено эмпирическое исследование с применением таких диагностических методик, как «Тест жизнестойкости С. Мадди» (адаптация Д.А. Леонтьева) [7], Многоуровневый личностный опросник «Адаптивность» А.Г. Маклакова и С.В. Чермянина (МЛО), Опросник ПДО (А.Е. Личко) и Тест FPI. Выборку испытуемых составили студенты 1-3-х курсов ДГУ и ДГМА (30 юношей и 30 девушек). Возраст респондентов 17-19 лет.

Корреляционный анализ (по Пирсону) показал наличие нескольких невысоких, но статистически значимых показателей связи между шкалами указанных методик. Причём все коэффициенты отрицательные (см. таблицу 1).

\section{Таблица 1. Коэффициенты корреляции между шкалами опросников «Тест жизнестойкости» МЛО, ПДО и FРI}

\begin{tabular}{|c|c|c|c|c|}
\hline Шкалы опросников МЛО, & \multicolumn{4}{|c|}{ Тест жизнестойкости С. Мадди } \\
\cline { 2 - 5 } ПДО и FРІ & Вовлечённость & Контроль & Принятие риска & Жизнестойкость \\
\hline Моральная нормативность & & &,$- 315^{*}$ & \\
\hline Реактивная агрессивность &,$- 292^{*}$ & &,$- 306^{*}$ &,$- 314^{*}$ \\
\hline Застенчивость & &,$- 284^{*}$ & & \\
\hline $\begin{array}{c}\text { Циклоидная акцентуация } \\
\text { характера }\end{array}$ &, $263^{*}$ & & \\
\hline $\begin{array}{c}\text { Лабильная акцентуация } \\
\text { характера }\end{array}$ & & &,$- 344^{* *}$ &,$- 256^{*}$ \\
\hline
\end{tabular}

"Корреляция значима на уровне 0,05 (двухсторонняя).

${ }^{* *}$ Корреляция значима на уровне 0,01 (двухсторонняя).

Рассмотрим каждый из них подробнее.

Первый значимый показатель - коэффициент корреляции между шкалой «принятие риска» и шкалой «моральная нормативность». Чем сильнее убежденность индивида в том, что любая жизненная ситуация, независимо от того, позитивный или негативный опыт она несет, одинаково ценна для ее личностного развития, тем труднее ему удается сочетать свои морально-нравственные нормы с нормами ближайшего социума $(r=-0,315)$.

Наибольшее количество значимых коэффициентов корреляции было выявлено при изучении взаимосвязи жизнестойкости с реактивной агрессивностью. Поскольку низкие значения по шкале реактивной агрессивности являются свидетельством повышенной значимости для индивида социальных норм, его постоянной привязанности к общественному мнению, его конформности, уступчивости, то отрицательные коэффициенты корреляции со шкалами вовлеченности $(r=-0,292)$, принятия риска $(r=-0,306)$ и общей жизнестойкости $(r=-0,314)$ можно рассматривать как закономерные. Приняв социальные нормы как собственные, индивиду не придется постоянно 
противостоять всему окружению, следовательно, меньше конфликтных или стрессовых ситуаций, выше уровень адаптивности.

Далее нами выявлен показатель связи между шкалами опросника FPI и шкалами опросника С. Мадди: высокие значения по фактору «Застенчивость» опросника FPI сочетаются с низкими значениями по шкале «Контроль» опросника С. Мадди $(r=-0,284)$. Лица с высокими оценками по фактору застенчивости являются носителями таких качеств, как неуверенность и нерешительность. Они избегают рискованных ситуаций и от любых перемен ожидают только неприятностей. Застенчивость мешает ясно мыслить и эффективно общаться; она, как правило, сопровождается негативными переживаниями одиночества, тревожности и депрессии [4]. Неуверенность в своих силах не позволяет застенчивому человеку осуществлять контроль над своей жизнью самостоятельно, без помощи близких людей. Страх перед ошибкой способствует не усилению контроля, а напротив, парализует сознательные механизмы управления своей жизнью. Поэтому описанная корреляция является лишним подтверждением валидности выбранного нами диагностического инструментария.

Изучение взаимосвязей между акцентуациями характера и структурными элементами жизнестойкости показало наличие небольшого количества значимых коэффициентов (см. таблицу 1). Черты циклоидности положительно коррелируют с контролем $(r=0,263)$. Юноши и девушки, тяжело переживающие любые неприятности, а также отличающиеся повышенной раздражительностью в ответ на критику, в большей степени уверены, что полностью самостоятельно осуществляют контроль за собственной жизнью.

Жизнестойкость связана с лабильной акцентуацией: чем меньше личность подвержена перепадам настроения, отличается эмоциональной стабильностью, тем выше показатели ее жизнестойкости $(r=-0,256)$. Здесь надо заметить, что выявленный нами коэффициент корреляции согласуется с результатами исследования Логиновой М.В. Изучая жизнестойкость в её взаимосвязи с личностными характеристиками, она установила, что чем выше жизнестойкость, тем ниже показатели эмоциональной возбудимости и ригидности [11].

Лабильная акцентуация также связана с компонентом жизнестойкости «принятие риска» $(r=-, 344)$. В описании данной акцентуации Личко А.Е. указывает на такие характерные для лабильных индивидов особенности, как порицания, осуждения, выговоры, нотации, которые глубоко переживаются и способны ввергнуть в беспросветное уныние [8]. На наш взгляд, стремление избегать ситуаций, приводящих к негативной оценке окружающих, сдерживает индивида, акцентуированного по данному типу, от рискованных действий. То есть именно страх перед наказанием не позволяет рассматривать риск как возможность приобретения жизненного опыта и как фактор личностного развития.

Таким образом, на основании результатов нашего исследования, можно заключить, что с жизнестойкостью и отдельными ее показателями закономерно связаны личностные характеристики, отвечающие за стрессоустойчивость, эмоциональную стабильность и адаптивные способности индивида.

Дальнейшие исследования феномена жизнестойкости, на наш взгляд, следует расширять как в сторону выявления и изучения факторов, способствующих формированию данной особенности личности, так и в сторону динамики развития структурных её элементов на различных возрастных этапах онтогенеза. 


\section{Литература}

1. Александрова Л.А. К концепции жизнестойкости в психологии // Сибирская психология сегодня: сб. научн. трудов. Вып. 2 / под ред. М.М. Горбатовой, А.В. Серого, М.С. Ясницкого. - Кемерово: Кузбассвузиздат, 2004. - С. 82-90.

2. Ванакова Г.В. Жизнестойкость как социальная и психологическая проблема личности // Среднее профессиональное образование. - 2013. - № 11. - С. 46-49.

3. Евтушенко E.A. Жизнестойкость личности как психологический феномен // Личность, семья и общество: вопросы педагогики и психологии. - 2016. - № 60. C. $72-78$.

4. Зимбардо Ф. Как побороть застенчивость. - М.: Альпина Диджитал, 2013.

5. Калашникова М.Б., Никитина Е.В. Жизнестойкость как необходимая личностная характеристика современных подростков // Вестник Новгородского государственного университета им. Я. Мудрого. - 2017. - № 4 (102). - С. 51-55.

6. Кудинов С.И., Кудинов С.М., Хаммад С.М. Жизнестойкость как предиктор самореализации личности в трудных жизненных ситуациях // Известия Саратовского университета. Новая серия. Акмеология образования. Психология развития. - 2017. Т. 6, № 3. - С. 229-238.

7. Леонтьев Д.А., Рассказова Е.И. Тест жизнестойкости. - М.: Смысл, 2006. $63 \mathrm{c}$.

8. Личко A.E. Психопатии и акцентуации характера у подростков. [Электронный pecypc]. - Режим доступа: http://www.psychology.ru/library/00034.shtml (Дата обращения: 9.03.18).

9. Маклаков А.Г. Личностный адаптационный потенциал: его мобилизация и прогнозирование в экстремальных условиях // Психологический журнал. - 2001. T. 22, № 1. - C. 16-24.

10. Никитина Е.А., Кузнецова А.А. Жизнестойкость как личностный ресурс студента в условиях высшей школы // Известия Юго-Западного государственного университета. Сер.: Лингвистика и педагогика. - 2014. - № 2. - С. 79-85.

11. Осин Е.Н., Рассказова Е.И. Краткая версия теста жизнестойкости: психометрические характеристики и применение в организационном контексте // Вестник МГУ. Сер. 14: Психология. - 2013. - № 2. - С. 147-165.

12. Фоминова А.Н. Жизнестойкость личности. - М.: Прометей, 2012. - 280 с.

Поступила в редакиџию 13 марта 2018 г.

UDC 159.9.072

DOI: $10.21779 / 2542-0313-2018-33-1-95-100$

\section{Hardiness in its relationship with the individual characteristics of person}

\section{M.K. Omarova}

Dagestan State University; Russia, 367001, Makhachkala, M. Gadzhiev st., 43a; makaom@mail.ru

The article is devoted to the study of the problem of hardiness of the individual. Special attention is paid to the study of the relationship of hardiness to different characteristics of the individual. 
Such features as character accentuations, adaptability, shyness, moral normativity are considered. Problem is studied in such fields of science as philosophy, psychology, medicine. In particular, we consider features such as accentuation of character, adaptability, shyness, moral normativity and others. Much attention is paid to hardiness in philosophy, a little less it is studied in psychology and medicine. For example, by representatives of medical science hardiness is considered as one of the indicators of mental health.

The article presents the results of an empirical study of the relationship of structural components of hardiness with the above personal characteristics. During the preparation of the work, the author used such methods as analysis of psychological literature, synthesis, generalization - theoretical methods; qualitative analysis of the results of the study - practical methods of the research. The study was conducted on a sample of students whose average age was 17-19 years. To obtain empirical data, we used techniques that were relevant to the goals and objectives set by us at the beginning of our work and possessed rather high levels of validity and reliability. The application of methods of mathematical processing made it possible to obtain reliable communication indicators at a high level of statistical significance. Analysis of the results showed the presence of stable correlation between structural elements of hardiness and the following personal characteristics: reactive aggressiveness, shyness, moral normativity, cycloidal and labile accentuation character. Thus, it can be concluded that personality characteristics that are responsible for the stress-resistance, emotional stability and adaptive abilities of the individual are naturally associated with vitality. Further studies of the phenomenon of resilience need to be expanded both in the direction of identifying and studying the factors that contribute to the formation of this particular personality, and in the direction of studying its formation and development in the early stages of ontogeny.

Keywords: hardiness, involvement, control, acceptance of risk, personal characteristics.

Received 13 March, 2018 